【电子与信息科学 / Electronics and Information Science】

\title{
深圳市不同类型公园服务评价及提升策略
}

\author{
刘 娟 ${ }^{1}$ ，殷 豪 ${ }^{1}$ ，曹可心 ${ }^{1}$ ，胡诗旸 ${ }^{2}$ ，欧阳底梅 ${ }^{3}$ ，陈义勇 ${ }^{1}$ \\ 1) 深圳大学建筑与城市规划学院, 广东深圳 518060 ; \\ 2) 深圳意向策划设计有限公司，广东深圳 $518054 ； 3$ ）深圳市公园管理中心，广东深圳 518039
}

摘 要: 为使城市公园服务贴合公众实际需求, 采用社交媒体公园点评文本数据, 基于网络文本分析 与重要性-满意度分析 (importance performance analysis, IPA) 方法, 研究公众对不同类型公园服务感知及需 求差异，探索公园质量提升对策. 获取大众点评网络平台上公众对深圳市主要公园的 1.5 万条共计 160 万 字的点评文本，通过高频词分析建立公园服务评价指标体系. 将文本中涉及的公园服务质量的感知要素按 照指标体系编码, 并以要素出现的频率为重要性, 要素评分的均值为满意度, 构建不同类型公园的服务质 量评价 IPA 模型. 结果表明, 深圳的公园在总体环境景观及硬件设施、安全、休敀设施和咨询服务等方面, 公众关注度和满意度高; 在配套服务设施与商业和文化等增值管理服务方面，公众仍有较高期待. 针对不 同类型和不同年代建成的公园，结合公众服务感知及需求差异，从配套基础设施和管理服务等方面提出了 针对性的提升策略.

关键词：城市规划；城市公园；服务质量评价；网络文本分析；重要性-满意度分析；服务需求

中图分类号：TU986.5 文献标志码：A doi：10.3724/SP. J. 1249.2021.04433

\section{Service evaluation and promotion strategies for different types of parks in Shenzhen}

\section{LIU Juan ${ }^{1}$, YIN Hao ${ }^{1}$, CAO Kexin ${ }^{1}$, HU Shiyang², OUYANG Dimei ${ }^{3}$, and CHEN Yiyong ${ }^{1}$}

1) School of Architecture and Urban Planning, Shenzhen University, Shenzhen 518060, Guangdong Province, P. R. China

2) Shenzhen Intention Design Co. Ltd, Shenzhen 518054, Guangdong Province, P. R. China

3 ) Shenzhen Park Management Center, Shenzhen 518039, Guangdong Province, P. R. China

\begin{abstract}
To make urban park servlies meet the practical needs of the public, this paper studies the differences in public perception and demand for different types of park services and explores counter measures to improve the park quality by the online text analysis method and importance performance analysis (IPA) method based on the social media park review text data. There are 15277 comment texts with 1.6 million words about Shenzhen's major parks from the public comment platfom Dianping. com that are used to establish a park service evaluation index system with high-frequency word analysis. The IPA model of Shenzhen park service quality evaluation is constructed by encoding the park service quality perception elements involved in the text according to the index system and taking the frequency of elements appearing as the importance and the average value of factor evaluation score as satisfaction degree. The results show that the public show higher attention and satisfaction on the overall environmental landscape
\end{abstract}

Received: 2020-09-01; Accepted: 2021-01-27; Online (CNKI) : 2021-06-04

Foundation: National Natural Science Foundation of China (51408367); Scientific Research Support Project of Shenzhen Municipal Bureau of Urban Management and Comprehensive Law Enforcement (201904)

Corresponding author: Associate professor CHEN Yiyong. E-mail: chenyiy@ szu.edu.cn

Citation: LIU Juan, YIN Hao, CAO Kexin, et al. Service evaluation and promotion strategies for different types of parks in shenzhen [J]. Journal of Shenzhen University Science and Engineering, 2021, 38(4) : 433-440. (in Chinese) 
and hardware facilities, safety, rest facilities and park consulting services in Shenzhen park. The public still have the higher expectations for supporting service facilities and value-added management services such as business and culture. Furthermore, this paper puts forward the targeted improvement strategies from supporting infrastructure and management services for different types of parks and parks built in different eras, combined with the public service perception and demand differences.

Key words: urban planning; urban park; service quality evaluation; web text analysis; importance performance analysis (IPA) ; service requirement

为突出不同人群的需求，《城市绿地分类标准》 （CJJ/T85-2017）将公园分为综合公园、社区公园 和专类公园等. 但是, 随着公园建设如火如茶，也 出现了一些问题，如传统的综合公园因建设年代久 远呈现 “综合老化” 的问题 ${ }^{[1]}$; 社区公园建设缺乏 全面、系统和科学合理的建设标准进行指导控 制 $^{[2]}$; 专类公园出现多元化和层级化等特征，但整 体上的充分性和不同地域间的均衡性均显不足 ${ }^{[3]}$ 等. 随着经济社会日益发展，人们对不同类别公园 的功能和服务需求更加细化, 需要深人探索公众对 不同类型公园的需求差异及提升策略.

传统的公园评价研究大多采用问卷调查方式获 取评价数据，存在问卷样本量小和采集时间较集中 等缺陷 ${ }^{[4]}$. 近年来许多研究者采用新数据、新方法 构建了公园服务评价指标体系并开展多方面公园服 务评价 ${ }^{[5]}$, 如王金等 ${ }^{[6]}$ 基于网络大数据利用词频分 析技术，对森林公园的社会服务价值进行评价；龙 奋杰等 ${ }^{[7]}$ 引人手机信令数据, 对公园的服务人数、 服务半径和服务有效性进行评价; ALBAYRAK 等 ${ }^{[8]}$ 提出基于绩效的评价模型探索游客动机和满意 度之间的关系.

随着大众媒体的发展和网络数据的普及, 客 观、真实且数据量大的网络文本分析替代了传统问 卷调查方法, 如新浪博客、携程网和马蜂窝等网站 的数据被用于网络语义分析、情感和旅游体验分
析 $^{[9]}$. 本研究以中国深圳市不同类别、不同年代建 成的公园为研究对象, 利用网络文本数据, 构建公 园服务评价指标体系, 采用重要性-满意度分析 (importance performance analysis, IPA) 模型, 研究 公众对不同类型公园服务感知及需求的差异，探索 网络文本数据在公园服务质量评价及提升对策中的 应用。

\section{1 数据与方法}

\section{1 研究对象选取}

截至 2020 年 8 月深圳已建成公园达 1206 个 $^{[10]}$. 综合比较大众点评网、携程网、蚂蜂窝网 及去哪儿网等多个网络平台后, 选取受众广、对公 园服务评论数据多的大众点评 (http://diangping. com) 网络平台作为数据来源. 将公众对深圳公园在 该评台有效的点评数量作为公众关注度，选取排名 前 30 的作为研究对象，如表 1. 这些公园涵盖了不 同类别和建设 (改造) 完成年代，具体分布请扫描论 文末页右下角二维码查看补充材料图 S1. 其中，城 市公园 18 个，社区公园 2 个，郊野公园 10 个; 1980-1989 年建设的 5 个，1990-1999 年建设的 10 个，2000-2009 年建设的 9 个，2010-2019 年 建设的 6 个.

表 1 研究对象基本情况及类别

Table 1 Basic information and category of research objects

\begin{tabular}{|c|c|c|c|c|c|c|c|c|c|}
\hline 名 称 & 点评数/条 & 建成年份 & 面积 $/ \mathrm{hm}^{2}$ & 类 型 & 名 称 & 点评数/条 & 建成年份 & 面积 $/ \mathrm{hm}^{2}$ & 类 型 \\
\hline 莲花山公园 & 2152 & 1997 & 181.00 & 郊野公园 & 东湖公园 & 509 & 1984 & 193.21 & 城市公园 \\
\hline 深圳湾公园 & 2008 & 2011 & 108.07 & 城市公园 & 荔枝公园 & 509 & 1982 & 30.00 & 城市公园 \\
\hline 深圳人才公园 & 1980 & 2017 & 77.00 & 城市公园 & 中山公园 & 337 & 1999 & 49.00 & 郊野公园 \\
\hline 大梅沙海滨公园 & 1554 & 1999 & 36.00 & 城市公园 & 南山公园 & 314 & 1982 & 352.00 & 郊野公园 \\
\hline 市民中心公园 & 1057 & 2004 & 91.00 & 城市公园 & 笔架山公园 & 286 & 1999 & 149.00 & 郊野公园 \\
\hline 洪湖公园 & 903 & 1984 & 59.15 & 城市公园 & 深圳中心公园 & 275 & 1998 & 116.80 & 城市公园 \\
\hline 红树林海滨生态公园 & 853 & 2000 & 26.67 & 郊野公园 & 人民公园 & 240 & 1983 & 10.60 & 城市公园 \\
\hline 香蜜公园 & 839 & 2017 & 42.40 & 城市公园 & 荔香公园 & 165 & 2000 & 22.00 & 城市公园 \\
\hline
\end{tabular}


(续表 1)

\begin{tabular}{ccccc||ccccc}
\hline 名 称 & \multicolumn{1}{c|}{ 点评数/条 } & 建成年份 & 面积 $/ \mathrm{hm}^{2}$ & 类 型 & 名 称 & 点评数/条 & 建成年份 & 面积 $/ \mathrm{hm}^{2}$ & 类 型 \\
\hline 大沙河公园 & 161 & 2007 & 31.20 & 城市公园 & 龙城公园 & 68 & 2006 & 189.00 & 郊野公园 \\
白石龙音乐公园 & 157 & 2019 & 11.60 & 城市公园 & 灵芝公园 & 65 & 1991 & 12.00 & 社区公园 \\
立新湖公园 & 134 & 2015 & 190.00 & 郊野公园 & 翠竹公园 & 63 & 1999 & 45.13 & 城市公园 \\
宝安公园 & 129 & 2005 & 72.50 & 城市公园 & 聚龙山公园 & 58 & 2009 & 113.00 & 郊野公园 \\
龙华公园 & 103 & 1992 & 20.00 & 城市公园 & 盐田中央公园 & 55 & 2014 & 7.70 & 城市公园 \\
红花山公园 & 96 & 2000 & 20.00 & 郊野公园 & 梅林公园 & 48 & 2001 & 121.00 & 郊野公园 \\
皇岗公园 & 79 & 1997 & 17.30 & 城市公园 & 布吉公园 & 30 & 1994 & 2.00 & 社区公园 \\
\hline
\end{tabular}

\section{2 网络文本数据获取及处理}

采用网友 2017-2019 年在大众点评网的点评 数据, 剔除与公园服务内容无关以及纯图片和文字 内容少 (少于 15 个字符) 且无意义的点评，最终 篮选出 30 个公园的 15277 条评论数据总计 1665 505 字, 作为本研究的原始数据. 针对文本数据建 立归并词库并合并同义词；再建立过滤词库，过滤 掉与研究内容无关的词汇; 最后开展高频词分析.

基于文本数据的高频词类型结构, 参考文献 $[5,11-16]$, 构建 5 大类共 41 个指标的深圳公园服
务评价指标体系, 见表 2 . 由于该服务评价指标体 系基于公众的点评文本, 因此更贴近公众对城市公 园服务的实际需求. 针对公众的感知评价, 结合李 克特量表法进行指标编码和评价赋值. 按照公众评 价内容, 将满意度等级分为非常满意、比较满意、 一般、不太满意和很不满意, 并分别赋值为 5、4、 $3 、 2$ 和 1 . 根据以上评分标准获得 41 个指标要素 的频次和总得分可扫描论文末页右下角二维码查看 表 S2.

表 2 基于公众需求的深圳公园服务评价指标体系

Table 2 Shenzhen Park service evaluation index system based on the public demand

\begin{tabular}{|c|c|c|c|c|}
\hline 总目标层 & 准则层 & 序号 & 指标层 & 指标描述 \\
\hline \multirow{19}{*}{$\begin{array}{l}\text { 基于公众 } \\
\text { 需求的公园 } \\
\text { 服务评价 }\end{array}$} & \multirow{2}{*}{$\begin{array}{l}\text { 区位 } \\
\text { 条件 }\end{array}$} & 1 & 外部交通便捷度 & 外部交通便捷,公园可达性良好 \\
\hline & & 2 & $\begin{array}{c}\text { 与周边休闲娱乐 } \\
\text { 游㮩资源的相联性 }\end{array}$ & 周边是否有良好的休闲娱乐游憩等公共服务设施资源 \\
\hline & \multirow{6}{*}{$\begin{array}{l}\text { 景观 } \\
\text { 环境 }\end{array}$} & 3 & 绿化 & 公园内绿色植物覆盖状况 \\
\hline & & 4 & 植物景观 & 植物种类、色彩丰富搭配合理 \\
\hline & & 5 & 山水风光 & 公园自然环境良好,如山景或水体景观优美 \\
\hline & & 6 & 建筑风格 & 建筑小品美观、具有观赏性 \\
\hline & & 7 & 人文景观 & 特色文化展示、历史文化名人雕塑、民风民俗活动、园区文化氛围 \\
\hline & & 8 & 夜景 & 亮化景观搭配合理且层次丰富 \\
\hline & \multirow{11}{*}{$\begin{array}{l}\text { 基础 } \\
\text { 设施 }\end{array}$} & 9 & 停车场规模 & 充足的停车位 \\
\hline & & 10 & 绿道设置 & 绿道系统完善, 能满足公众的需求 \\
\hline & & 11 & 健身设施设置 & 健身设施 (塑胶跑道、健身路径等) 良好, 种类丰富且数量充足 \\
\hline & & 12 & 休鄎设施设置 & 休㮩设施和场地的设计人性化,数量足够且便利 \\
\hline & & 13 & 无障碍设施设置 & 完善的无障碍设施 \\
\hline & & 14 & 则所设置 & 公共则所的数量充足、位置便利且服务完善 \\
\hline & & 15 & 垃圾箱设置 & 垃圾箱的数量足够且位置便利 \\
\hline & & 16 & 标识系统设置 & 良好的标识导览系统引导公众 \\
\hline & & 17 & 照明设施设置 & 良好的照明环境 \\
\hline & & 18 & 遮阳避雨设施 & 良好的遮阳避雨设施 \\
\hline & & 19 & 娱乐设施丰富度 & 娱乐休闲的设施丰富多样 \\
\hline
\end{tabular}


（续表 2)

\begin{tabular}{|c|c|c|c|c|}
\hline 总目标层 & 准则层 & 序号 & 指标层 & 指标描述 \\
\hline \multirow{22}{*}{$\begin{array}{c}\text { 基于公众 } \\
\text { 需求的公园 } \\
\text { 服务评价 }\end{array}$} & \multirow{4}{*}{$\begin{array}{l}\text { 基础 } \\
\text { 设施 }\end{array}$} & 20 & 游憩娱乐空间多样性 & $\begin{array}{l}\text { 拥有完整的能满足家庭、中老年、情侣、青年和儿童的社交娱乐场 } \\
\text { 所,娱乐休息的空间丰富多样 }\end{array}$ \\
\hline & & 21 & 餐饮便民设施设置 & 便利的餐饮美食服务, 便民设施 (如洗手盆和直饮水等设施) 完善 \\
\hline & & 22 & 科教设施设置 & 多样的科教设施,促进不同人群的交流 \\
\hline & & 23 & 安全设施设置 & 公园内有良好的安全设施和警示语 \\
\hline & \multirow{8}{*}{$\begin{array}{l}\text { 游憩 } \\
\text { 环境 }\end{array}$} & 24 & 空间尺度 & 公园给人感觉整体空间的大小 \\
\hline & & 25 & 空间视野 & 供人俯视、仰视和眺望的辽阔的视觉空间 \\
\hline & & 26 & 空气质量 & 良好的空气质量 \\
\hline & & 27 & 区域空间拥挤感 & 公园局部空间拥挤感或空旷感 \\
\hline & & 28 & 游憩活动多样性 & 公众进行的游鄎活动的丰富度 \\
\hline & & 29 & 游客素质 & 游客素质良好 \\
\hline & & 30 & 空间实用性 & $\begin{array}{l}\text { 同一空间内复合多种功能, 且限制少 (如草坪可供游客休憩娱 } \\
\text { 乐),游客能进行多种活动,使人不易厌倦 }\end{array}$ \\
\hline & & 31 & 区域空间环境体验 & $\begin{array}{l}\text { 环境氛围亲切良好, 能满足不同人群的心理和身理感知需求, 以 } \\
\text { 及游客二次游园意愿 }\end{array}$ \\
\hline & \multirow{10}{*}{$\begin{array}{l}\text { 管理 } \\
\text { 服务 }\end{array}$} & 32 & 停车管理服务 & 规范的停车管理 \\
\hline & & 33 & 游客咨询服务 & 有方便游客投诉与咨询服务的管理处 \\
\hline & & 34 & 治安管理 & 治安环境和安全氛围良好 \\
\hline & & 35 & 休咊娱乐设施维护水平 & 休息和娱乐设施日常管理维护良好 \\
\hline & & 36 & 环境卫生维护水平 & 环卫工人充足, 环境卫生清洁度保持良好 \\
\hline & & 37 & 安全设施维护水平 & $\begin{array}{l}\text { 公共设施设计和材料把控严谨,水景的水深符合规范要求, 周边 } \\
\text { 配套设施已做防滑处理 }\end{array}$ \\
\hline & & 38 & 内部交通组织管理水平 & 交通组织良好, 人车分离, 能保障游客安全 \\
\hline & & 39 & 容量控制 & 对园区客流量进行管理 \\
\hline & & 40 & 噪音控制 & 动静分区且实施减噪管理, 满足不同人群的活动需求 \\
\hline & & 41 & 自然资源维护水平 & 园林养护和水资源保护良好 \\
\hline
\end{tabular}

\subsection{IPA 模型}

IPA 模型的分析结果形象直观，易于发现问题 并提供决策. 已有学者采用 IPA 模型，对主题或森 林公园的各要素进行分析, 得出亟待改善的因 素 ${ }^{[17-18]}$. 本研究将 IPA 模型应用于城市公园评价 中，根据评价指标的 $I$ 值和 $P$ 值制作 4 象限图. 设 $I$ 为公众对指标要素的关注和重视程度; $P$ 为公众对 指标要素的满意情况, 数学表达式分别为

$$
\begin{aligned}
& I=(n / N) \times 100 \% \\
& P=M / n
\end{aligned}
$$

其中, $n$ 为单个评价指标要素被提及的频次; $N$ 为所 有评价指标要素被提及的频次之和; $M$ 为单个评价 指标要素的总评分.

为检验指标要素的重要性与满意度差别是否具 有统计学意义, 对 41 项评价指标要素打分数据进
行配对样本 $t$ 检验，这些指标的显著性水平说明不 同要素差异显著程度不同 (表 3)。从双尾显著性概 率 (sig 双侧) 结果可见, 41 项指标要素均有显著性 差异 $(\operatorname{sig}$ 双侧 $<0.05)$ ，即指标要素的公众期望值 和满意度之间存在显著差异. $t<0$ 的指标要素，可 初步判断其满意度达到期望值.

表 3 公园服务评价要素的重要性和满意度值

Table 3 The importance and satisfaction value of park service evaluation elements

\begin{tabular}{cccccc}
\hline 编号 & 指标要素 & $I / \%$ & $P$ & $t$ & $\operatorname{sig}$ 双侧 \\
\hline 1 & 外部交通便捷度 & 4.15 & 4.03 & 3.597 & 0.000 \\
& $\begin{array}{c}\text { 与周边休闲娱乐 } \\
\text { 游䄭资源相关联性 }\end{array}$ & 3.44 & 4.21 & -5.936 & 0.000 \\
3 & 绿化 & 6.26 & 4.48 & 10.492 & 0.000 \\
4 & 植物景观 & 4.14 & 4.17 & -8.486 & 0.000 \\
\hline
\end{tabular}


(续表 3)

\begin{tabular}{|c|c|c|c|c|c|}
\hline 编号 & 指标要素 & $I / \%$ & $P$ & $t$ & $\operatorname{sig}$ 双侧 \\
\hline 5 & 山水自然风光 & 5.68 & 4.04 & 6.438 & 0.000 \\
\hline 6 & 建筑风格 & 0.79 & 4.07 & -1.395 & 0.021 \\
\hline 7 & 人文景观 & 4.67 & 4.20 & 4.485 & 0.018 \\
\hline 8 & 夜景 & 4.62 & 4.57 & 5.789 & 0.000 \\
\hline 9 & 停车场规模 & 1.14 & 2.89 & -2.358 & 0.003 \\
\hline 10 & 绿道设置 & 2.96 & 4.02 & -1.665 & 0.000 \\
\hline 11 & 健身设施设置 & 3.06 & 3.92 & -12.237 & 0.000 \\
\hline 12 & 休鄎设施设置 & 2.29 & 3.88 & -5.885 & 0.000 \\
\hline 13 & 无障碍设施设置 & 0.73 & 3.63 & -1.057 & 0.000 \\
\hline 14 & 公共则所设置 & 1.95 & 3.58 & -4.207 & 0.000 \\
\hline 15 & 垃圾箱设置 & 0.97 & 3.59 & -2.336 & 0.000 \\
\hline 16 & 标识系统设置 & 1.31 & 2.67 & -1.864 & 0.000 \\
\hline 17 & 照明设施设置 & 0.87 & 3.10 & -5.757 & 0.000 \\
\hline 18 & 遮阳避雨设施 & 2.14 & 2.87 & -2.741 & 0.000 \\
\hline 19 & 娱乐设施丰富度 & 2.75 & 3.60 & -2.889 & 0.007 \\
\hline 20 & 娱乐空间多样性 & 4.04 & 3.63 & 6.112 & 0.000 \\
\hline 21 & 餐饮便民设施设置 & 1.91 & 3.41 & -5.667 & 0.000 \\
\hline 22 & 科教设施设置 & 0.88 & 4.39 & -1.845 & 0.000 \\
\hline 23 & 安全设施设置 & 0.86 & 4.28 & -1.773 & 0.000 \\
\hline 24 & 空间尺度 & 1.59 & 3.88 & -3.093 & 0.039 \\
\hline 25 & 空间视野 & 3.59 & 4.23 & -5.447 & 0.000 \\
\hline 26 & 空气质量 & 5.62 & 4.39 & 14.230 & 0.000 \\
\hline 27 & 区域空间拥挤感 & 2.34 & 2.18 & 2.446 & 0.017 \\
\hline 28 & 游咊活动多样性 & 2.94 & 3.90 & -2.379 & 0.000 \\
\hline 29 & 游客素质 & 1.62 & 2.12 & -2.052 & 0.000 \\
\hline 30 & 空间实用性 & 4.12 & 4.28 & -8.364 & 0.000 \\
\hline 31 & 区域空间环境体验 & 6.75 & 3.93 & 12.884 & 0.000 \\
\hline 32 & 停车管理服务 & 0.52 & 3.08 & -2.367 & 0.000 \\
\hline 33 & 游客咨询服务 & 0.65 & 3.99 & -3.071 & 0.000 \\
\hline 34 & 治安管理 & 1.29 & 4.60 & -2.354 & 0.031 \\
\hline 35 & $\begin{array}{c}\text { 休蒩娱乐 } \\
\text { 设施维护水平 }\end{array}$ & 0.70 & 3.72 & -0.878 & 0.000 \\
\hline 36 & 环境卫生维护水平 & 3.08 & 3.94 & -6.335 & 0.000 \\
\hline 37 & $\begin{array}{l}\text { 安全设施 } \\
\text { 维护水平 }\end{array}$ & 0.40 & 3.92 & -1.313 & 0.002 \\
\hline 38 & $\begin{array}{c}\text { 内部交通 } \\
\text { 组织管理水平 }\end{array}$ & 0.22 & 3.35 & -0.954 & 0.001 \\
\hline 39 & 容量控制 & 0.68 & 3.40 & -1.436 & 0.000 \\
\hline 40 & 噪音控制 & 0.49 & 3.24 & -1.154 & 0.009 \\
\hline 41 & $\begin{array}{c}\text { 自然生态 } \\
\text { 资源维护水平 }\end{array}$ & 2.61 & 3.37 & -4.256 & 0.000 \\
\hline
\end{tabular}

\section{2 公众对公园服务需求分析}

\section{1 公园服务质量评价的 IPA 模型分析}

以深圳公园的各指标要素的重要性为横轴, 满 意度 (绩效表现) 为纵轴, 并以重要性的均值 $\bar{I}=2.44 \%$ 与满意度的均值 $\bar{P}=3.74$ 分别作为两坐 标轴原点, 构建 IPA 四象限图如图 1. 其中, 第 1 象限为高重要性且高满意度区, 体现公众最关注的 要素; 第 4 象限为高重要性但低满意度区, 体现公 众对公园关注但亟待改善提升的要素.

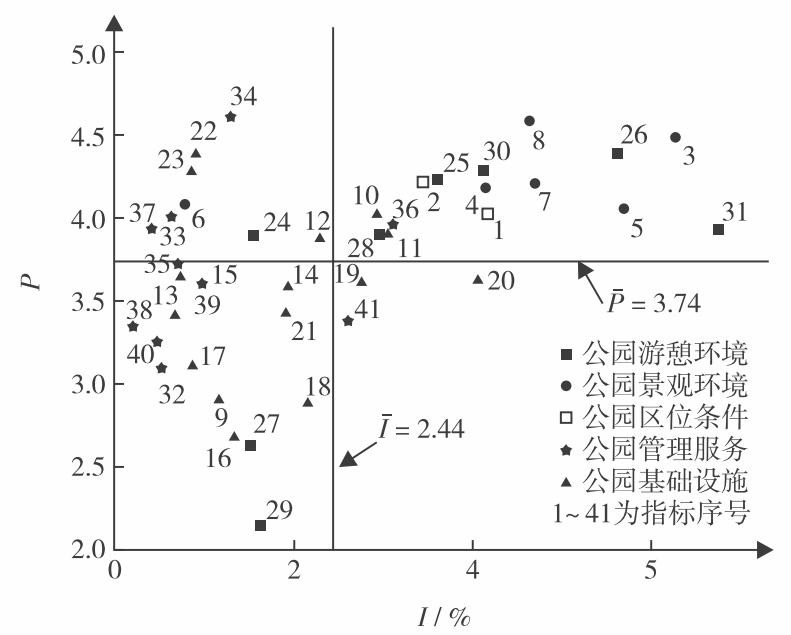

\section{图 1 深圳公园服务评价指标要素 IPA 模型 \\ Fig. 1 IPA model of service evaluation index elements in Shenzhen park}

由图 1 可见，第 1 象限包含的 15 个指标要素, 表明环境景观及硬件设施受到高度关注，得到了公 众的充分肯定. 满足这些条件的公园自然风光优 美, 人文景观有特色, 且为公众提供了必要的健身 设施，能让公众进行基本休喤娱乐活动. 第 4 象限 包含的 3 个指标要素是公众认为影响其心理和身理 感知的重要因素. 这些要素的满意度较低, 表明若 无改善会导致公众对公园整体服务的不满, 是公园 未来亟需改善提升的内容.

总体而言, 深圳公园的环境景观及硬件设施、 安全、休憩设施和公园咨询服务方面已到达较高服 务水平, 公众关注度和满意度也较高, 但仍在各类 配套服务设施与增值管理服务方面有较高期待, 是 未来提升的重点.

\section{2 不同类型公园服务质量评价的 IPA 模型}

根据各类别公园不同要素的重要性和满意度指 标, 构建 IPA 四象限图 (图 2). 由图 2 可见, 不同类 
别公园落在 4 个象限的评价指标要素各不相同, 体 现了公众对不同类型公园的关注要素和需求差异.

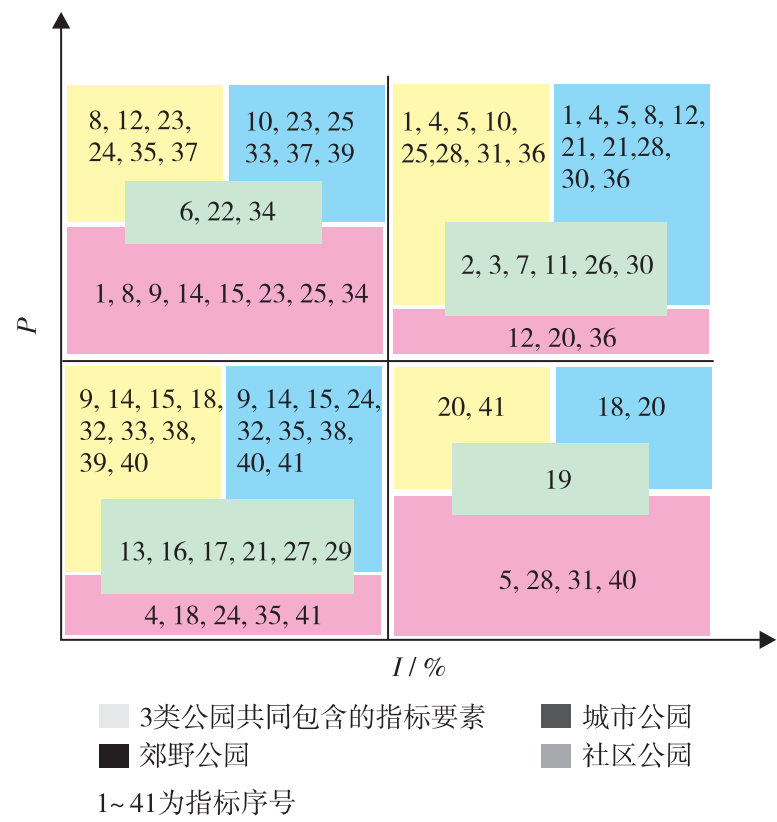

图 2 不同类型公园 IPA 四象限要素

Fig. 2 (Color online) Four quadrant elements of IPA in different types of parks

对于城市公园，公众最关注人文景观、夜景和 区域空间环境体验，说明景观质量和游䄭环境受关 注程度较高, 且满意度较好, 应继续维持相关服务 投人. 第 4 象限的遮阳避雨设施、娱乐设施丰富 度、娱乐空间多样性，需采取相应措施，以优化公 众的游憩体验.

对于社区公园，公众最关注公园绿化、娱乐设 施丰富度、娱乐空间多样性和空间实用性，即基础 设施和游憩环境. 其中, 娱乐空间多样性与山水风 光、游馣活动多样性、空间环境体验和公园噪音控 制都在第 4 象限，说明公众对公园提供这些要素的 服务方面感到不满意.

对于郊野公园，公众最关注区域空间环境体 验、公园绿化、公园空气质量和山水自然风光等景 观质量和游䄭环境指标，且满意度较高. 第 4 象限 的娱乐设施丰富度、娱乐空间多样性和自然资源维 护水平，也是影响景区整体满意度的关键因素，亟 待改善.

\section{3 不同建成年代公园服务质量评价的 IPA 模型}

分别选取建成于 1980-1989 年、1990-1999 年、2000-2009 年和 2010-2019 年 4 个时期的典 型公园，计算各类公园的要素关注度和满意度，构
建 IPA 四象限图如图 3. 由图 3 可见, 对于不同年 代建成的公园，公众的关注点存在一定差异.

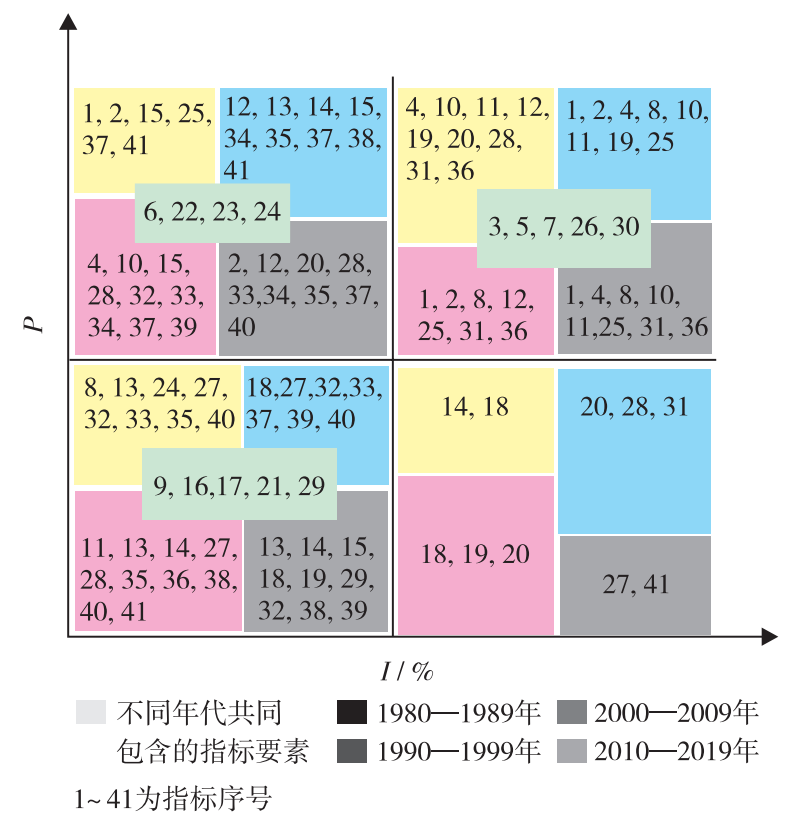

图 3 不同年代建成的公园 IPA 四象限要素

Fig. 3 (Color online) Four quadrant elements of park IPA built in different ages

1980-1989 年建成的公园，公众最关注空间实 用性、娱乐空间多样性、游憩活动多样性、植物景 观和人文景观，说明游咊环境和基础设施受关注程 度高，且满意度也高，需继续保持. 位于第 4 象限 的公共则所设置和遮阳避雨设施等基础设施存在不 足，是亟待改善的指标.

1990-1999 年建成的公园，公众最关注公园空 气质量、区域空间环境体验、公园绿化、植物景观 和人文景观等游敀环境和景观质量指标，且较为满 意. 游憩娱乐空间多样性、游惒活动多样性和区域 空间环境体验位于第 4 象限，可见，公众对游憩多 样性和部分基础设施不太满意, 需优化及完善.

2000-2009 年建成的公园，公众最关注公园夜 景、人文景观、与周边游咊资源关联性和外部交通 便捷度，说明公众更注重这类公园的景观质量和区 位条件，且由于公园的相关设计和服务较为完善， 公众对这些指标的满意度较高. 但位于第 4 象限的 遮阳避雨设施、娱乐设施丰富度和游蒩娱乐空间多 样性等基础设施，未能满足公众的期待.

2010-2019 年建成的公园，公众最关注山水自 然风光、公园绿化、区域空间环境体验、外部交通 便捷度和空间视野，表明公众更注重公园景观质量 和游憩环境, 且满意度高, 需要继续保持. 位于第 
4 象限的有区域空间拥挤感和自然资源维护水平, 这是导致公园负面评价的关键因素, 需要重点优化 和提升这些要素的服务水平.

总体而言，公众对早期建成的公园，游咊环境 和景观质量的满意度高，但其遮阳避雨设施等基础 设施及游䄭活动多样性还有待提升. 对于近期建成 的公园，夜景和人文景观等方面得到公众特别关 注，但新公园多存在较为拥挤和维护差等问题，同 时公园的管理服务方面需要格外注重.

\section{3 公园服务提升策略}

采用网络社交数据研究公众对不同类型公园服 务感知及需求差异，探索公园质量提升对策. 结果 表明, 深圳公园的环境景观、硬件设施、安全和休 悡设施，以及公园咨询服务方面都已达到较高服务 水平，公众关注度和满意度高; 各类配套服务设施 与增值管理服务方面，公众仍有较高期待；不同类 型公园有相似的短板，如基础设施方面停车场规 模、公共则所设置、标识系统设置、照明设施设置、 遮阳避雨设施和停车管理服务等仍需提升. 为此, 结合 IPA 分析，针对深圳公园提出以下提升策略：

1）城市公园的环境景观及硬件设施受到公众 高度关注，并已得到充分肯定，但交通管理、商业 服务和文体设施等增值服务仍需进一步提升，如加 强公园的交通管理，包括停车场设置、停车管理、 对内对外交通组织，以及必要的公众容量控制等. 逐步增加公园特色服务设施供给，扩展公园增值服 务，如遮阳避雨设施、体育运动设施、必要的商业 售卖、丰富多样的文化艺术展览活动，以及咖啡茶 座等饮食服务. 配置符合不同人群需求的服务设 施，如针对不同人群配置的文娱设施、体育休憩设 施和儿童活动设施等. 此外，公园的自然山水风 光、人文景观要素、夜景照明、空气质量、空间环 境体验、绿道和健身设施、卫生环境维护、照明设 施、无障碍设施、公共则所和标识系统等配套设施 也需要加强.

2) 对于不同类型的公园，由于资源禀赋条件 差异，公众关注的重点略有差异，服务提升亦应各 有侧重. 城市公园需提高可达性, 增加垃圾箱、直 饮水和自动售卖机等设施，完善健身休憩设施，做 好公园运动设施和休憩设施更新维护的工作. 社区 公园需增设和完善无障碍设施，体现对特殊人群的 关怀，为中老年人开辟专门的歌、舞等休闲区域，
适当设置儿童游乐场地，还可以通过开展演艺活 动、传统节日活动和艺术展览等，为公众提供良好 的休闲、娱乐和社交环境. 郊野公园需重点关注停 车难问题, 并合理布局体育运动区, 配备各类集运 动性、趣味性、竞技性和文化性为一体的健身器 材，营造全民运动健身的氛围.

3) 对于不同年代建成的公园，景观环境、设 施供给和维护存在较大差异, 公众关注的重点和不 满意的焦点也差异明显. 早期建成的公园，在照明 和遮阳避雨设施设置、标识和游㤩娱乐设施的维护 与更新等基础设施建成方面有待提升，游憩活动多 样性也应加强. 近期建成的公园, 存在拥挤和维护 差等问题，休欯娱乐设施维护、停车服务和管理、 商业和文化服务方面也需重点关注.

基金项目: 国家自然科学基金资助项目 (51408367); 深圳市城市 管理和综合执法局科研基金资助项目 (201904)

作者简介：刘 娟 (1996-), 深圳大学硕士研究生. 研究方向 公共空间建设. E-mail: 1195758304@ qq. com

引文：刘 娟，殷 豪，曹可心，等. 深圳市不同类型公园服 务评价及提升策略 $[\mathrm{J}]$. 深圳大学学报理工版, 2021,38 (4) : 433-440

\section{参考文献 / References :}

[1] 刘 源，王 浩，汪 辉. 城市综合公园 “有机更 新”初探——以青岛㲸水山城市绿谷设计为例 $[\mathrm{J}]$. 林业科技开发，2012，26：113-117.

LIU Yuan, WANG Hao, WANG Hui. A preliminary exploration of "organic renewal" of urban comprehensive parks: urban green valley design with Qingdao Zhushuishan $[\mathrm{J}]$. Journal of Forestry Engineering, 2012, 26: 113-117. (in Chinese)

[2]王菊萍，谢良生. 深圳市社区公园建设与发展研究 [J]. 中国园林，2009，25(12)：69-71.

WANG Juping, XIE Liangsheng. A research on construction and development of community park in Shenzhen city $[\mathrm{J}]$. Chinese Landscape Architecture, 2009, 25 (12): 69-71. (in Chinese)

[ 3 ] 李云超, 王忠杰, 刘纾萌, 等. 专类公园发展趋势及 规划建设应对的思考 $[\mathrm{J}]$. 中国园林，2020，36(12)： 35-40.

LI Yunchao, WANG Zhongjie, LIU Shumeng, et al. Thoughts on the development trends and planning and construction of theme parks $[\mathrm{J}]$. Chinese Landscape Architecture, 2020, 36(12) : 35-40. (in Chinese)

[ 4 ] 王志芳, 赵稼楠, 彭瑶瑶, 等. 广州市公园对比评价 研究一一基于社交媒体数据的文本分析 $[\mathrm{J}]$. 风景园 林, 2019, 26(8) : 89-94.

WANG Zhifang, ZHAO Jianan, PENG Yaoyao, et al. Comparative evaluation of Guangzhou city parks: text analysis based on social media data $[\mathrm{J}]$. Landscape 
Architecture, 2019, 26(8) : 89-94. (in Chinese)

[5]孙艺嘉, 吴雪飞. 城乡结合部综合公园公共服务评价 研究一一武汉市白玉公园为例 $[\mathrm{J}]$. 建筑与文化, 2016(10) : 195-197.

SUN Yijia, WU Xuefei. Park public service evaluation of urban-rural fringe comprehensive park: an example on Wuhan White Jade Park [J]. Architecture \& Culture, 2016(10): 195-197. (in Chinese)

[6]王 金金, 李 雄. 基于网络大数据的北京森林公园社 会服务价值评价研究 $[\mathrm{J}]$. 中国园林, 2017，33(10): 14-18.

WANG Xin, LI Xiong. Research on the analysis of social services value of forest park in Beijing based on network big data $[\mathrm{J}]$. Chinese Landscape Architecture, 2017, 33(10): 14-18. (in Chinese)

[ 7 ] 龙奋杰, 石 朗, 彭智育, 等. 基于手机信令数据的 城市公园服务评价 $[\mathrm{J}]$. 城市问题, 2018(6) : 88-92.

LONG Fenjie, SHI Lang, PENG Zhiyu, et al. Service evaluation on urban parks based on the cellular signaling data $[\mathrm{J}]$. Urban Problems, 2018 (6) : 88-92. (in Chinese)

[ 8 ] ALBAYRAK T, CABER M. Examining the relationship between tourist motivation and satisfaction by two competing methods $[\mathrm{J}]$. Tourism Management, 2018, 69: 201-213.

[9]敬峰瑞, 孙 虎, 龙冬平. 基于网络文本的西溪湿地 公园旅游体验要素结构特征分析 $[\mathrm{J}]$. 浙江大学学报 理学版, 2017, 44(5): 623-630.

JING Fengrui, SUN Hu, LONG Dongping. Tourist experience elements structure characteristics analysis of Xixi National Wetland Park based on web text $[\mathrm{J}]$. Journal of Zhejiang University Science Edition, 2017, 44 (5) : 623-630. (in Chinese)

[10］深圳市城市管理和综合执法局. 深圳公园概况 [EB/ OL]. (2021-02-25). http://cgj. sz. gov. cn/xsmh/szgy/gygy/content/post_2127756. html.

Shenzhen Municipal Urban Management and Comprehensive Law Enforcement Bureau. Overview of Shenzhen park $[\mathrm{EB} / \mathrm{OL}] .(2021-02-25)$. http://cgj. sz. gov. cn/ xsmh/szgy/gygy/content/post_2127756. html. ( in Chinese)

[11] 毛小岗, 宋金平, 冯徽徽, 等. 基于结构方程模型的 城市公园居民游憩满意度 $[\mathrm{J}]$. 地理研究, 2013，32 (1) : 166-178.

MAO Xiaogang, SONG Jinping, FENG Huihui, et al. Residents recreation satisfaction index of Beijing city parks based on SEM [J]. Geographical Research, 2013, 32 (1) : 166-178. (in Chinese)

[12] 肖 星, 杜 坤. 城市公园游㮩者满意度研究一以 广州为例 $[\mathrm{J}]$, 人文地理, 2011, 26(1) : 129-133.

XIAO Xing, DU Kun. A study on recreationists' statisfaction of Guangzhou city parks $[\mathrm{J}]$. Human Geography, 2011, 26(1): 129-133. (in Chinese)

[13] 梁明珠, 刘志宏. 城市人工湿地景区休闲游憩价值评
价—以广州市南沙湿地公园为例 $[\mathrm{J}]$. 城市问题, 2014(7) : 37-42.

Liang Mingzhu, LIU Zhihong. Evaluation of leisure and recreation in urban constructed wetland scenic spots: a case study of Nansha Wetland Park, Guangzhou [ J ] . Urban Problems, 2014(7) : 37-42. (in Chinese)

[14]王 敏, 彭 英. 基于游憩机会谱理论的城市公园体 系研究——以安徽省宁国市为例 $[\mathrm{J}]$. 规划师, 2017, 33(6) : 100-105.

WANG Min, PENG Ying. A study on city park system based on recreation opportunity spectrum theory: Ningguo City, Anhui province [J]. Planners, 2017, 33(6) : 100105. (in Chinese)

[15] 赵 静, 宣国富. 城市居民公园游憩体验质量及性别 差异一以南京玄武湖公园为例 $[\mathrm{J}]$. 中国园林, 2015, 31(7): 113-116.

ZHAO Jing, XUAN Guofu. Experience quality and gender differences of the urban park-based recreation: a case study of Xuanwu Lake Park in Nanjing $[\mathrm{J}]$. Chinese Landscape Architecture, 2015, 31(7) : 113-116. (in Chinese)

[16] 俞 䂀, 汪 芳. 城市园林游唕活动谱研究一一无 锡市为例 $[\mathrm{J}]$. 中国园林, 2008, 24(4): 84-88.

YU Xi, WANG Fang. A research on recreation activity spectrum of urban parks: a case study of Wuxi City [J]. Chinese Landscape Architecture, 2008, 24 (4) : 84-88. (in Chinese)

[17] MARTILLA J A, JAMES J C. Importance-performance analysis [J]. Journal of Marketing, 1977, 41: 77-79.

[18] 辛 欣, 陈 楠. 基于 IPA 方法的文化主题公园旅游 项目优化研究一以开封清明上河园为例 $[\mathrm{J}]$. 资源 科学, 2013, 35(2): 321-331.

XIN Xin, CHEN Nan. A positivist study on cultural theme park tourism optimization using IPA methods in Kaifeng Millennium City Park [J]. Resources Science, 2013, 35 (2) : 321-331. (in Chinese)

[19］黄淑萍, 葛鈜华, 刘芬菲, 等. 千岛湖国家森林公园 游㴧资源评价与提升策略研究 $[\mathrm{J}]$. 林业资源管理, 2019(1) : 123-128.

HUANG Shuping, GE Hongye, LIU Fenfei, et al. Research on recreational resources evaluation and improvement of Qiandao Lake National Forest Park [ J ]. Forest Resources Management, 2019 ( 1 ): 123-128. (in Chinese)

【中文责编：英 子; 英文责编: 木 柯】 